\title{
Improved Analytic Hierarchy in Water Diversion Scheme
}

\author{
Qingqing Zhang
}

North China Electric Power University, Baoding 071003, China

rukawakaede723@163.com

Keywords: Water Shortage; Improved Analytic Hierarchy; Beijing.

\begin{abstract}
This paper is to propose a water diversion scheme to alleviate the shortage of water resources. We select six main reservoirs around Beijing, consider each reservoir characteristic parameter and use Improved Analytic Hierarchy Process to calculate the weight which can fix the problem of subjectivity caused by conventional methods. And we regard the weight as reservoir water transfer ratio. In this model, we use relative proportion to calculate the scale. By this way, we avoid the influence of subjectivity. In the end, the water transfer ratio about different reservoirs is presented. Xidayang reservoir accounts for $21.34 \%$ of reservoir water supply, providing the largest amount of water.
\end{abstract}

\section{Introduction}

We list the main reservoirs around Beijing and use the Improved Analytic Hierarchy Process (IAPH) ${ }^{[1]}$ to get our decision-making project of reservoir water supply distribution. We improve the traditional Analytic Hierarchy Process (AHP) ${ }^{[2][3]}$ and use numerical ratio that have the same dimension to calculate the scale. Finally we work out the optimal allocation of water supply according to the relationship of each weight vector. This method avoids the subjectivity when selecting the scale.

\section{Improved Analytic Hierarchy Process (IAHP)}

\subsection{Model Design}

In order to get a intervention plan to improve Beijing' s water situation, we adopt the Improved Analytic Hierarchy Process (IAHP), focus on the reservoir water diversion and select six main reservoirs around Beijing ${ }^{[4][5]}$ to establish a model and get specific measures.

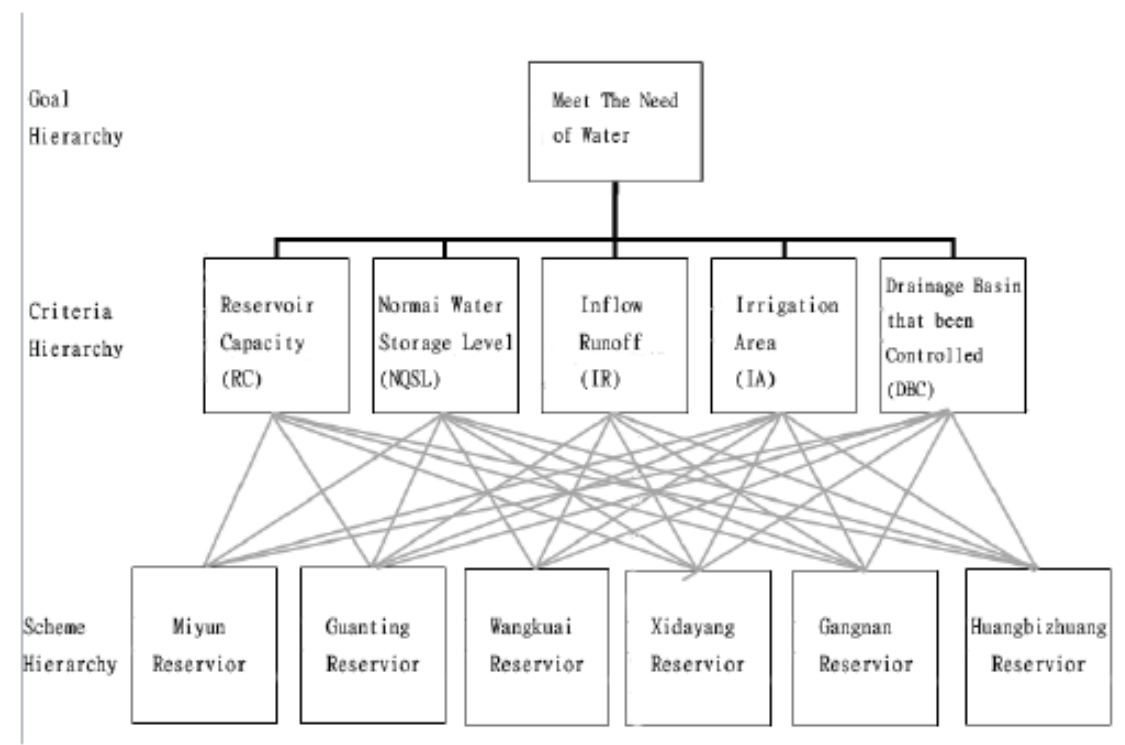

Figure 1: Hierarchical structure. 
Table 1: Selection criteria of the scale

\begin{tabular}{|c|c|}
\hline scale & implication \\
\hline 1 & Factor $\mathrm{i}$ and $\mathrm{j}$ have equal value; \\
\hline 3 & Factor $\mathrm{i}$ has a slightly higher value than $\mathrm{j} ;$ \\
\hline 5 & Factor $\mathrm{i}$ has a strongly higher value than $\mathrm{j} ;$ \\
\hline 7 & Factor $\mathrm{i}$ has a very strongly higher value than $\mathrm{j} ;$ \\
\hline 9 & Factor $\mathrm{i}$ has an absolutely higher value than $\mathrm{j} ;$ \\
\hline $2,4,6,8$ & Intermediate scales between two adjacent judgments; \\
\hline Reciprocals & Factor $\mathrm{i}$ has a lower value than $\mathrm{j} ;$ \\
\hline
\end{tabular}

\subsection{Calculation}

\subsubsection{Set up the Weight Vector between Goal Hierarchy and Criteria Hierarchy}

According to the importance of these five indexes (not giving unnecessary details because o length of the article), we have the paired comparison matrix of goal hierarchy toward criteria hierarchy:

$$
A=\left[\begin{array}{ccccc}
1 & 4 / 5 & 4 & 4 / 5 & 4 / 3 \\
5 / 4 & 1 & 5 & 1 & 5 / 3 \\
1 / 4 & 1 / 5 & 1 & 1 / 5 & 1 / 3 \\
5 / 4 & 1 & 5 & 1 & 5 / 3 \\
3 / 4 & 3 / 5 & 3 & 3 / 5 & 1
\end{array}\right]
$$

Then we use MATLAB and obtain the maximal characteristic root of A:

$\lambda_{\mathrm{m}}=5$

The sum of characteristic roots $\mathrm{N}=5$. The corresponding normalized values of the weight vector is:
$W_{A}=[0.2222$
0.2778
0.0556
0.2778
$0.1667]^{T}$

\subsubsection{Calculation the Model}

When selecting the scale, we improved the traditional Analytic Hierarchy Process AHP. The traditional method determine the influence of each criterion through artificial judgement and it is inevitable to have a subjective influence on the result. We improve the traditional method to have a more objective selection of scale.

Firstly, we do proportional calculation to the values with the same dimension, then calculate the relative proportion as the scale. The specific calculation method is as follows:

Set $\mathrm{p}_{i j}$ as the index value $\mathrm{j}$ of scheme $\mathrm{i} ; \sigma_{\mathrm{ij}}$ as the proportion of the criterion value $\mathrm{j}$ of scheme $\mathrm{i}$ for the criterion value $\mathrm{j}$ of all schemes. That is:

$$
\delta_{\mathrm{ij}}=\frac{p_{i j}}{\sum_{i=1}^{6} p_{i j}}
$$

$\eta_{i j}$ means the relative proportion of scheme i toward scheme i - 1 .

$$
\eta_{\mathrm{ij}}= \begin{cases}1 & \mathrm{i}=1 \\ \frac{\delta_{\mathrm{i}-1 \mathrm{j}}-\delta_{\mathrm{ij}} * 10}{\delta_{\mathrm{ij}}} & \mathrm{i} \geq 2\end{cases}
$$

Calculate the criterion value accounts for the proportion of the total criterion value of six scheme hierarchies and determine the weight matrix. 


\begin{tabular}{|l|l|l|l|l|}
\hline \multirow{2}{*}{} & \multicolumn{3}{|l|}{ reservolr capacity ( a hundred million $\mathrm{m}^{ }$) } & \multicolumn{2}{l|}{ normal water storage level(m) } \\
\cline { 2 - 5 } & first-hand data & proportion & first-hand data & proportion \\
\hline $\begin{array}{l}\text { Miyun } \\
\text { Reservoir }\end{array}$ & 40 & 0.3479 & 157.5 & 0.1214 \\
\hline $\begin{array}{l}\text { Guanting } \\
\text { reservoir, }\end{array}$ & 21.9 & 0.1905 & 479 & 0.3692 \\
\hline $\begin{array}{l}\text { Wangkuai } \\
\text { reservoir }\end{array}$ & 13.89 & 0.1208 & 200.4 & 0.1545 \\
\hline $\begin{array}{l}\text { West Ocean } \\
\text { reservoir }\end{array}$ & 11.37 & 0.0989 & 140.5 & 0.1083 \\
\hline $\begin{array}{l}\text { Gangnan } \\
\text { reservoir }\end{array}$ & 15.71 & 0.1366 & 200.0 & 0.1542 \\
\hline $\begin{array}{l}\text { Huan gbizhua } \\
\text { ng reservoir }\end{array}$ & 12.10 & 0.1052 & 120 & 0.0925 \\
\hline total & 114.97 & 1 & 1297.4 & 1 \\
\hline
\end{tabular}

\begin{tabular}{|l|l|l|l|l|l|}
\hline \multicolumn{2}{|l|}{$\begin{array}{l}\text { inflow runoff(a hundred million } \\
\left.\mathrm{m}^{2}\right)\end{array}$} & \multicolumn{2}{|l|}{ Irrigation area(milion mu) } & \multicolumn{2}{l|}{$\begin{array}{l}\text { drainage basin that been } \\
\text { controlled }(\mathrm{k} \mathrm{m})^{2}\end{array}$} \\
\hline first-hand data & proportion & first-hand data & proportion & first-hand data & proportion \\
\hline 9.5 & 0.1442 & 200 & 0.2789 & 15778 & 0.1431 \\
\hline 3.0 & 0.0455 & 150 & 0.2092 & 47000 & 0.4262 \\
\hline 7.5 & 0.1138 & 140 & 0.1953 & 3770 & 0.0342 \\
\hline 7.8 & 0.1184 & 50 & 0.0697 & 4420 & 0.0401 \\
\hline 16.6 & 0.2519 & 20 & 0.0279 & 15900 & 0.1442 \\
\hline 21.5 & 0.3263 & 157 & 0.2190 & 23400 & 0.2122 \\
\hline 65.9 & 1 & 717 & 1 & 110268 & 1 \\
\hline
\end{tabular}

Figure2: Schemes and indexes

Illustrated by the example of reservoir capacity, we can work out the scale according to the proportion:

For Miyun Reservoir account for the largest share, we take its scale for 1.Then we calculate the relative value of other reservoirs toward Miyun Reservoir:

Guanting Reservoir:(0.3479 $\quad 0.1905) / 0.3479 \times 10=4.524$, take scale for 4 .

Wangkuai Reservoir:(0.1366_ 0.1208$) / 0.1366 \times 10=1.157$, take scale for 1 .

West Ocean Reservoir:(0.1052 - 0.0989)/0.1052 $\times 10=0.060$, take scale for 1 .

Gangnan Reservoir:(0.1905 $\quad 0.1366) / 0.1905 \times 10=2.829$, take scale for 3 .

Huangbizhuang Reservoir:(0.1208_ 0.1052)/0.1208 $\times 10=1.291$, take scale for 1 .

So we have the paired comparison matrix of reservoir-capacity criterion toward scheme hierarchy:

$$
\mathrm{B}_{1}=\left[\begin{array}{cccccc}
1 & 1 / 4 & 1 & 1 & 1 / 3 & 1 \\
4 & 1 & 4 & 4 & 4 / 3 & 4 \\
1 & 1 / 4 & 1 & 1 & 1 / 3 & 1 \\
1 & 1 / 4 & 1 & 1 & 1 / 3 & 1 \\
3 & 3 / 4 & 3 & 3 & 1 & 1 \\
1 & 1 / 4 & 1 & 1 & 1 & 1
\end{array}\right]
$$

Then we use MATLAB to obtain the maximal characteristic root of $B_{1}$ :

$$
\lambda_{1 m}=6.1414 \text {. }
$$
is:

The sum of characteristic roots $\mathrm{N}=6$.The corresponding normalized values of the weight vector

$$
W_{\mathrm{B}_{1}}=\left[\begin{array}{llllll}
0.0921 & 0.3682 & 0.0921 & 0.0921 & 0.2378 & 0.1179
\end{array}\right]^{T}
$$

The same procedure may be easily adapted to comparison matrix of other criterion.

Analysis their consistency index CI: 


$$
\mathrm{CI}=\frac{\lambda_{m}-n}{n-1}
$$

Compare with the random consistency index RI and we get consistency rate CR:

$$
\mathrm{CR}=\frac{\mathrm{CI}}{\mathrm{RI}}
$$

When $\mathrm{CR} \leqslant 0.1$, we can think that the consistency of $\mathrm{A}$ is within the allowable range and the normalized feature vector can be used as the weight vector.

The following data are satisfied with the consistency check and five groups of paired comparison matrix are consistency matrix, shows the accuracy of the relationship between criterion hierarchy and scheme hierarchy.

Table 2: Table for consistency check

\begin{tabular}{|c|c|c|c|c|c|}
\hline & RC & NWSL & IR & IA & DBC \\
\hline $\mathrm{n}$ & & & & & \\
\hline $\mathrm{CI}$ & 0.0283 & & & & \\
\hline $\mathrm{RI}$ & 1.24 & 1.24 & 1.24 & 1.24 & 1.24 \\
\hline $\mathrm{CR}$ & 0.0228 & & & & \\
\hline
\end{tabular}

\subsubsection{Combination Weight Vector}

$\mathrm{W}=\mathrm{W}_{\mathrm{B}} * \mathrm{~W}_{\mathrm{A}}$

And we have: $W=\left[\begin{array}{llllll}0.1063 & 0.1514 & 0.1884 & 0.2134 & 0.2087 & 0.1318\end{array}\right]^{T}$

\section{Conclusion}

According to our model, we got the optimal water diversion scheme of water supply for Beijing area, and the distribution of each reservoir water supply is shown in Figure 3.

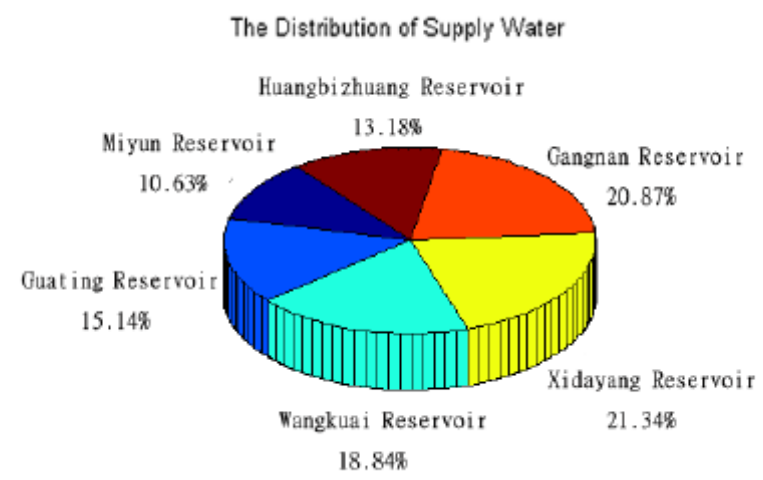

Figure 3: The distribution of each reservoir water supply.

\section{References}

[1]. LiYanShuang, ZengZhenXiang, ZhangMin, YuShuJiang. Application of Primary Component Analysis in the Methods of Comprehensive Evaluation for many Indexes. Journal of HeBei University of Technology, 1999, 28(1):94-97.

[2]. SiShoukui, SunXijing. Mathematical Modeling,2011

[3]. ZHANG Ji-jun. Fuzzy Analytical Hierarchy Process. FUZZY SYSTEMS AND MATHEMATICS, 2000, 14(2):80-88.

[4]. The Ministry of Water Resources of the People' s Republic of China. China Water Resources Bulletin, 2002-2014.

[5]. BEIJING WATER AUTHORITY. Beijing Water Resources Bulletin, 2002-2014. 